\title{
Narbona metropolis: Grenzen zwischen kirchlichen Interessen und weltlicher Herrschaftsbildung
}

\author{
URSULA VONES-LIEBENSTEIN
}

Caeterum Alfonsus, Hispaniae Citerioris rex, Burgensem episcopum Tarraconensi metropolitano nequaquam patiebatur esse subjectum, ea de causa quod infra regni sui terminos Burgus sit, Tarracona autem in Barcinonensis comitis potestate ${ }^{1}$.

'Im übrigen würde es Alfons, der König der Hispania Citerior, niemals erlauben, daß der Bischof von Burgos dem Metropoliten von Tarragona unterworfen würde, da Burgos in seinem Königreich liegt, Tarragona aber im Machtbereich des Grafen von Barcelona'. Dieses Zitat aus einer Urkunde Papst Urbans II., in der die exemte Stellung von Burgos festgeschrieben wird, zeigt symptomatisch auf, welche Probleme sich für das Papsttum aus dem Bestreben weltlicher Herrscher ergaben, ihre Landesbischöfe nicht einem Metropoliten außerhalb ihres eigenen Machtbereichs zu unterstellen. Das Wissen um die alten Diözesanzugehörigkeiten, um die früheren kirchlichen Grenzen, lag noch vor, stimmte aber keineswegs immer mit der politischen Landkarte des ausgehenden 11. und beginnenden 12. Jahrhunderts überein, wie sie sich nach der Reconquista ergeben hatte. Übten kirchliche Genzen eine Wirkung ,für die Stabilisierung von herrschaftlichen Territorien aus“, wie sich Hans-Joachim Schmidt, in seinem umfassenden Werk über die „Raumgliederung der Kirche im mittelalterlichen Europa“ fragte ${ }^{2}$ ? Diente eine Übereinstimmung zwischen kirchlichen und weltlichen Grenzen also der Herrschaftssicherung und wurde sie in diesem Sinne in Septimanien, das einst zum westgotischen Reich gehört hatte, genutzt?

Der Versuch, eine solche Übereinstimmung zu erzielen, blickte auf eine lange Tradition zurück. ${ }^{3}$ Schon im vierten Kanon des Konzils von Nikaia von 325 wurde die Gleichsetzung von weltlichen und kirchlichen Verwaltungseinheiten festgeschrieben, mit dem Ziel, daß alle Bischöfe einer Provinz einem Metropoliten unterstehen sollten, der in der Provinzhauptstadt residier-

1 JL. 5653, MPL 151, Sp. 471, Nr. 201 von 1096 Juli 15 in Nîmes.

2 Kirche, Staat, Nation. Raumgliederung der Kirche im mittelalterlichen Europa, Weimar 1999 (Forschungen zur mittelalterlichen Geschichte 37), S. 37.

3 So u. a. Simon T. Loseby: Bishops and cathedrals: order and diversity in the fifthcentury urban landscape of southern Gaul, in: Fifth-century Gaul: a crisis of identity?, hg. v. John F. DRINKWATER/ Hugh Elton, Cambridge 1992, S. 144-150, hier S. 144. 
te. ${ }^{4}$ Bei politischen Veränderungen hielten entgegen der herkömmlichen Meinung $^{5}$ eine Reihe von Päpsten bis Gelasius I. an der Unveränderlichkeit „kirchlicher Zugehörigkeiten und kirchlichen Besitzes“ fest ${ }^{6}$, dies änderte jedoch nichts daran, daß die durch die Gründung von Germanenreichen auf römischem Boden bedingten Umwälzungen durchaus zu einer Anpassung kirchlicher und weltlicher Grenzen führen konnten. ${ }^{7}$ Setzte doch noch Gratian in der immer wieder kontrovers diskutierten Dekretale Scitote im 12. Jahrhundert provincia mit regnum gleich. ${ }^{8}$

4 Schmidt: Kirche, Staat, Nation (wie Anm. 2), S. 41; Conciliorum oecumenicorum decreta, hg. v. Giuseppe Alberigo u. a., 4. Aufl., Bologna 1996, c. IV-VI, S. 7-9. Javier HervadA: Significado actual del principio de la territorialidad, in: Fidelium Iura 2 (1992) S. 221-239, hier 222-225; Ciro TAMMARO: La giurisdizione episcopale nell'alto medioevo. Riflessioni sul principio ,un solo vescovo per città' sancito dal can. VIII del Concilio de Nicea I (325), in: Ius Canonicum 46 (2006) S. 623-636, bes. S. 630-633; Michel LaUWERS: Territorium non facere diocesim. Conflits, limites et représentation territoriale du diocèse $\left(\mathrm{V}^{\mathrm{e}}-\mathrm{XIII}{ }^{\mathrm{e}}\right.$ siècle), in: L'espace du diocèse. Genèse d'un territoire dans l'Occident médiéval $\left(\mathrm{V}^{\mathrm{e}}-\mathrm{XIII}{ }^{\mathrm{e}}\right.$ siècle), hg. v. Florian MAZEL, Rennes 2008, S. 23-65, hier S. 23f.

5 Karl MÜllER: Kleine Beiträge zur alten Kirchengeschichte 18. Parochie und Diözese im Abendland in spätrömischer und merowingischer Zeit, in: Zeitschrift für neutestamentliche Wissenschaft und die Kunde der älteren Kirche 32 (1933) S. 149-185.

6 Heike GRAHN-HoEK: Quia Dei potentia cunctorum regnorum terminos singulari dominatione concludit. Kirchlicher Einheitsgedanke und weltliche Grenzen im Spiegel der reichsfränkischen Konzilien des 6. Jahrhunderts, in: Religiöse Bewegungen im Mittelalter, FS für Matthias Werner zum 65. Geburtstag, hg. v. Enno BÜNZ/ Stefan TeBRUCK/ Helmuth G. WALTHER, Köln 2007 (Veröffentlichungen der Historischen Kommission für Thüringen. Kleine Reihe 24; Schriftenreihe der Friedrich-Christian-LesserStiftung 19), S. 3-54, hier S. 45, wies gegenüber MüllER: Kleine Beiträge (wie Anm. 5) überzeugend nach, daß weder Papst Zosimus (417/8) noch die Päpste Innocenz I. und Gelasius I. immer bereit waren, kirchliche und weltliche Grenzen einander anzupassen.

7 GraHN-Hoeck: Kirchlicher Einheitsgedanke (wie Anm. 6), verfolgt diese Fragestellung vor allem anhand der Reichsteilungen in merowingischer Zeit und betont dabei, daß die Forderung der Bischöfe auf dem Konzil von Clermont (535), Besitz nicht nur innerhalb ihres Teilreiches, sondern auch in Gebieten anderer Herrscher zu haben (S. 11), durchaus der Einheit des fränkischen Gesamtreiches förderlich war (S. 15f.). Zum Konzil von Clermont vgl. die Edition der Konzilsakten von Friedrich MAASEN: Concilia aevi Merovingici, 2. Aufl. Hannover 1956 (MGH Conc. I), S. 65-71, hier besonders den Brief der versammelten Bischöfe an König Theudebert, S. 71.

8 SchmidT: Kirche, Staat, Nation (wie Anm. 2), S. 52f., der jedoch betont, daß „diejenigen, die kirchliche Bezirke, insbesondere Provinzen, an weltliche Herrschaftsgebiete anzugleichen bestrebt waren", diese Dekretale nicht als Begründung heranzogen. Corpus iuris canonici I, Decreti secunda pars, c. VI, q. 3, c. 2 Quot cinitates unaqueque prouincia habeat, hg. v. Emil FriedBerg, Leipzig 1879 (Nachdr. Graz 1959), Sp. 562. Siehe Raymonde FOREVILlE: Royaumes, métropolitains et conciles provinciaux. France, Grande-Bretagne, Péninsule ibérique, in: Le istituzioni ecclesiastiche della «Societas christiana» dei secoli XI-XII. Papato, cardinalato e episcopato. Atti della 5a set- 


\section{Die Entwicklung der Kirchenprovinz Narbonne von der Spätantike bis zur Integration ins Frankenreich}

Die Kirchenprovinz Narbonne, die Narbonnensis prima, die erstmals um 400 in der Notitia provinciarum mit den Suffraganen Toulouse, Béziers, Nîmes, Lodève und Uzès genannt wurde ${ }^{9}$, zählte nach 462, als der römische Heermeister Ricimer Septimanien den Westgoten überließ, um ihre Unterstützung zu gewinnen $^{10}$, zum westgotischen regnum von Toulouse. Als das Zentrum des Westgotenreiches nach der Niederlage König Alarichs II. gegen die Franken Chlodwigs in der Schlacht von Vouillé (507) nach Toledo verlegt wurde, führte dies zu einer Orientierung Septimaniens auf Spanien hin. Im 6. Jahrhundert, vor dem Übertritt König Rekkareds zum katholischen Glauben $(587)^{11}$, kam es zur Abspaltung der Bistümer Agde von Béziers, Carcassonne von Narbonne und Maguelonne von Nîmes. ${ }^{12}$ All diese Bischöfe, einschließ-

timana internazionale di studio, Mendola 26-31 agosto 1971, Mailand 1974 (Miscellanea del Centro di studi medioevali 7), S. 272-313, hier S. 292f.

9 Notitia Galliarum, in: Chronica minora saec. IV. V. VI. VII., hg. v. Theodor MommSEN, Hannover 1892 (MGH AA IX), S. 552-612, hier S. 559, wo Narbonne, Toulouse, Béziers, Nîmes und Lodève angeführt werden und v. a. S. 608f., wo Narbonne als metropolis civitas den civitates Toulouse, Béziers, Nîmes und Lodève sowie dem castrum Uzès übergeordnet wird, wobei in einigen Handschriften Elne, Agde und Maguelonne als civitates hinzugefügt werden und Lodève und Arisitum jeweils als castrum bezeichnet werden. Siehe dazu den Artikel und die Neuedition von Jill HARRIES: Church and State in the Notitia Galliarum, in: The Journal of Roman Studies 68 (1978) S. 26-43. Auf die Bedeutung der Notitia für die von Urban II. (JL. 5688) und Paschalis II. (JL. 5808 und 6157) bestätigten Primatsansprüche Narbonnes über die Kirchenprovinz Aix, für die von Calixt II. 1119/1120 betonten Primatsansprüche von Vienne u. a. über die Narbonnensis und für die erstmals auf dem Konzil von Reims 1148 vorgetragenen Primatsansprüche von Bourges über die Narbonnensis kann in diesem Zusammenhang nicht eingegangen werden. Siehe dazu Fabrice DelivRÉ: The Foundations of Primatial Claims in the Western Church (Eleventh-Thirteenth Centuries), in: JEcH 59 (2008) S. 383-406, hier vor allem S. 401 und 403-405; Henri VIDAL: Les origines de la primatie narbonnaise $\left(\mathrm{XI}^{\mathrm{e}}-\mathrm{XII}{ }^{\mathrm{e}}\right.$ siècles), in: Narbonne: Archéologie et histoire. Narbonne au Moyen-Âge ( $=\mathrm{XLV}^{\mathrm{e}}$ Congrès de la Fédération Historique du Languedoc Méditérannéen et du Roussillon), Montpellier 1973, S. 121-127, sowie Georges PARISET: L'établissement de la primatie de Bourges, in: AM 14 (1902) S. 145-184 und 289328.

10 Siehe zu Ricimer Dirk HenNing: Periclitans res publica: Kaisertum und Eliten in der Krise des Weströmischen Reiches 454/5-493 n. Chr., Stuttgart 1999 (Historia: Einzelschriften 133), S. 75.

11 Siehe zu Rekkared Dietrich Claude: Adel, Kirche und Königtum im Westgotenreich, Sigmaringen 1971, S. 77-91.

12 Die Gründe für dieses Phänomen, das etwa zeitgleich auch zur Abspaltung Egaras von Barcelona führte, lagen sowohl in den inneren Machtverhältnissen im Westgotenreich begründet als auch in der Tatsache, daß die Bischofssitze in den civitates zu dieser Zeit wahrscheinlich von arianischen Bischöfen besetzt waren. Siehe dazu Josep Maria 
lich des Bischofs von Elne und mit Ausnahme der Bischöfe von Uzès und Toulouse ${ }^{13}$, erschienen zum ersten 589 von Rekkared nach Toledo einberufenen Konzil. ${ }^{14}$ Auch die Liturgie der Bistümer der Narbonnensis richtete sich künftig an den Gewohnheiten der westgotischen Kirche aus, da ein Kanon des IV. Toletanum bestimmte, daß die Feier des Gottesdienstes innerhalb eines Königreiches nicht unterschiedlich sein solle nec diversa sit ultra in nobis ecclesiastica consuetudo qui una fide continetur et regno; hoc enim et antiqui canones decreverunt, ut unaquaeque provincia et psallendi et ministrandi parem consuetudinem teneat ${ }^{15}$.

Die politischen Veränderungen hatten auch Einfluß auf die Provinzialgrenzen. Die seit 507 zum regnum der Franken zählenden Bischofssitze Toulouse und Uzès gehörten von da an bis zur Eingliederung der Kirchenpro-

MARTí BONET: Els orígens del Bisbat d'Égara, in: Simposi Internacional sobre les Esglésies de Sant Pere de Terrassa. Actes, Terrassa 1992, S. 61-71; Anscari Manuel Mundó i MARCET: El Bisbat d'Ėgara de l'època tardo-romana a la carolíngia, ebd., S. 41-49, hier S. 42-44; sowie Sebastian SCHOLZ: Transmigration und Translation. Studien zum Bistumswechsel der Bischöfe von der Spätantike bis zum Hohen Mittelalter, Köln/ Weimar/ Wien 1992, S. 61-63 und Laurent SCHNEIDER: Cités, campagnes et centres locaux en Gaule narbonnaise aux premiers siècles du Moyen Age ( $\mathrm{V}^{\mathrm{e}}-\mathrm{IX}{ }^{\mathrm{e}} \mathrm{s}$.): une nouvelle géographie, de nouveaux liens, Saragossa 2006, S. 2f., der von einem allgemein zu beobachtenden „morcellement de l'espace régional“ und einem „profond bouleversement de l'organisation territoriale antique et des anciennes hiérachies urbaines“ spricht, während LAUWERS: Conflits (wie Anm. 4), S. 5 die ,plasticité des territoires ecclésiaux" und Hans-Joachim SCHMIDT: Grenzen in der mittelalterlichen Kirche. Ekklesiologie und juristische Konzepte, in: Grenzen und Raumvorstellungen (11.-20. Jh.) - Frontières et conceptions de l'espace (XI'- $\mathrm{XX}^{\mathrm{e}}$ siècles), hg. v. Guy P. MARCHAL, Luzern 1996, S. 137-162, hier S. 140-143, die Ablösung kirchlicher Strukturen von römischen Verwaltungseinheiten betonen.

13 Noch im 9. Jh. war in Nordspanien bekannt, welche Bistümer zur Kirchenprovinz Narbonne zählten: Gallia quoque non est de prouintias Spanie, sed sub regimine Gotorum erat ita: Narbona metropoli, Beterris, Agate, Magalona, Niumaso, Luteba, Carcassona, Elena, Tolosa (Chronica Albendensia, in: Crónicas asturianas, hg. v. Juan GIL FERNÁNDEZ, Oviedo 1985 [Publicaciones del Departamento de Historia Medieval 11], S. 154 und Chronique d'Albelda, in: Chroniques asturiennes [fin IX ${ }^{\mathrm{e}}$ siècle], hg. v. Yves BonNAZ, Paris 1987 [Sources d'histoire médiévale publiées par l'IRHT], S. 11).

14 Siehe die Akten bei José VIVES: Concilios visigóticos e hispano-romanos, Madrid 1963, S. 185-188. Vgl. auch Paul-Albert FÉvrier/ Xavier BARRAl i Altet: Topographie chrétienne des cités de la Gaule des origines au milieu du VIII ${ }^{\mathrm{e}}$ siècle, Bd. VII: Province ecclésiastique de Narbonne (Narbonnensis prima), Paris 1989, S. 13, wobei Février betont, daß wir seit dieser Zeit anders als im Rest Südfrankreichs über gut dokumentierte Bischofslisten verfügen; Reinhold KAISER: Bischofsherrschaft zwischen Königtum und Fürstenmacht: Studien zur bischöflichen Stadtherrschaft im westfränkisch-französischen Reich im frühen und hohen Mittelalter, Bonn 1981 (PHS 17), S. 258f.; sowie Emilienne Demougeot: La Septimanie dans le royaume wisigotique de la fin du $\mathrm{V}^{\mathrm{e}}$ à la fin du VII ${ }^{\mathrm{e}}$ s., in: Actes des $\mathrm{IX}^{\mathrm{e}}$ Journées d'Archéologie Mérovingienne: Gaule Mérovingienne et Monde Méditerranéen (Lattes, Septembre 1987), Publication du Musée Archéologique de Lattes 1988, S. 1-39, hier S. 22.

15 VIVES: Concilios (wie Anm. 14), S. 188, Kanon II. 
vinz Narbonne ins Frankenreich zu den Kirchenprovinzen Bourges und Arles. ${ }^{16}$ Vom Bistum Nîmes dagegen, das noch ins westgotische Reich integriert war, wurde 535 Arisitum mit 15 Pfarreien abgespalten, als König Sigebert von Austrien für einen gewissen Munderich, der nach einer zwiespältigen Bischofswahl Langres verlassen mußte, ein eigenes Bistum schaffen wollte. ${ }^{17}$ Erst nach dem Sieg Karl Martells über die Mauren wurde Arisitum erneut ins Bistum Nîmes integriert und verschwand aus der Geschichte, weshalb es auch später in der Divisio Wambae nicht angeführt wurde. Von Lodève ist nur bekannt, daß es von 535 bis 580 in fränkischer Hand war und daß sein Bischof 635 am Konzil von Clermont teilnahm. ${ }^{18} \mathrm{Ob}$ es zwischenzeitlich einer anderen Kirchenprovinz zugeordnet war, ist nicht überliefert. Allgemein läßt sich für diese Frühzeit feststellen, daß bei der Neu- und Umgestaltung der Kirchenprovinz Narbonne die Wechselfälle der politischen Zugehörigkeit zu den regna der Westgoten oder Franken die entscheidende Rolle spielten.

\section{Die Wiedererrichtung der Kirchenprovinz Tarragona: Girona, Barcelona, Vic, Urgell und Elne (als Sonderfall)}

Durch die Eingliederung Kataloniens und Septimaniens ins Frankenreich im 8. Jahrhundert kam es zu einer Ablösung der westgotischen Kirchenstrukturen. Der Metropolitansitz von Tarragona, dem in der Frühzeit nicht nur die katalanischen Bistümer Barcelona, Egara, Urgell, Girona und Ausona-Vic unterstellt waren, sondern auch Tortosa, Saragossa, Tarazona, Calahorra, Pamplona, Huesca, Lérida und Empurien ${ }^{19}$, war von Ludwig dem Frommen bei seinem Zug nach Katalonien nicht zurückerobert worden. Narbonne selbst hatte zwar

16 Fevrier/ Barral i Altet: Topographie chrétienne (wie Anm. 14), S. 12.

17 Demougeot: La Septimanie (wie Anm. 14), S. 21 betont, daß 535 die Bischöfe von Lodève und Arisitum am Konzil von Clermont teilnahmen, während der Bischof von Uzès 535 und 554 an Konzilien in Orléans und 552 in Paris teilnahm. Vgl. auch Eugen EWIG: Die fränkischen Teilungen und Teilreiche (511-613), Mainz 1953 (AAMz 9), Neudr. in: DERS.: Spätantikes und fränkisches Gallien. Gesammelte Schriften, hg. v. Hartmut Atsma, 2 Bde., München 1976 (Beihefte der Francia 3), Bd. 1, S. 72-113). Zu Arisitum, das 535 erstmals bezeugt ist, als Nimes noch zum westgotischen Reich zählte, vgl. Jules QUiCHERAT: Remarques sur quelques noms de lieux des monnaies mérovingiennes, in: BEC 28 (1867) S. 105-123, hier S. 108f., und SCHNEIDER: Cités (wie Anm. 12), S. 11.

18 Demougeot: La Septimanie (wie Anm. 14), S. 21 und 24.

19 Vgl. Luis VazQuez de Parga: La División de Wamba. Contribución al estudio de la historia y geografia eclesiástica de la Edad Media española, Madrid 1943, S. 30. Obwohl in der vorliegenden Form erst Ende des 11./ Anfang des 12. Jh.s entstanden, kann man davon ausgehen, daß die Divisio durchaus auf älteren Quellen gründet, da sonst nicht verständlich wäre, wieso die Bischofssitze von Egara und Empurien, die bereits im 9. Jh. untergingen, angeführt sind. 
759 den Franken seine Tore geöffnet, jedoch kann man davon ausgehen, daß der Metropolitansitz erst nach 811 wiederhergestellt wurde, da Narbonne neben Aix als einzige Metropole im Testament Karls des Großen keine Erwähnung fand. ${ }^{20}$ In einer kaiserlichen Verfügung von 817 war dann die Rede davon, daß Barcelona, Girona, Besalú und Empurien-Roussillon zur Narbonnensis, Urgell-Cerdanya dagegen zu Aquitanien zählten. ${ }^{21}$ Aber erst siebzig Jahre später stand fest, daß diese Bistümer Narbonne angeschlossen würden. Dazu bedurfte es der Zusammenarbeit zwischen Graf Wifred el Pilós von Barcelona und Erzbischof Theodard von Narbonne, die beide der gleichen fränkischen Adelsfaktion angehörten. Wifred strebte die Eingliederung der katalanischen Bistümer zur Absicherung seiner Herrschaftsansprüche $a^{22}$, während Erzbischof Theodard systematisch am Ausbau seiner Metropolitanstellung arbeitete, die er durch königliche und päpstliche Privilegierung absichern lie $\beta^{23}$. Der Versuch Graf Borells I. von Barcelona, dies mit Hilfe Papst Johannes' XIII. hundert Jahre später, um 970, wieder rückgängig zu machen und durch die Übertragung der Metropolitanrechte Narbonnes für die vier katalanischen Bistümer auf den Bischofssitz von Ausona-Vic ${ }^{24}$ erneut eine Übereinstimmung zwischen kirchlichem und weltlichem Herrschaftsgebiet zu errei-

20 Heinrich BÜTTNER: Mission und Kirchenorganisation des Frankenreiches bis zum Tode Karls des Großen, in: Karl der Große. Lebenswerk und Nachleben, hg. v. Helmut BeumanN u. a., Bd. I, Düsseldorf 1965, S. 454-487, hier S. 485; vgl. auch Ursula VONES-LIEBENSTEIN: Katalonien zwischen Maurenherrschaft und Frankenreich. Probleme um die Ablösung westgotisch-mozarabischer Kirchenstrukturen, in: Das Frankfurter Konzil von 794, hg. v. Rainer BERNDT, Mainz 1997 (Quellen und Abhandlungen zur mittelrheinischen Kirchengeschichte 80), S. 447-498, hier S. 471f. Zur Wiedererrichtung des Metropolitansitzes von Narbonne siehe jetzt Daniel Carlo PANGERL: Die Metropolitanverfassung des karolingischen Frankenreiches, Hannover 2011 (MGH Schr. 63), S. 93-96.

21 Vones-Liebenstein: Katalonien (wie Anm. 20), S. 472, v. a. Anm. 106 mit Literatur und Belegen.

22 Vgl. Vones-Liebenstein: Katalonien (wie Anm. 20), S. $488 \mathrm{f}$.

23 Robert-Henri BautieR: Recueil des Actes d'Eudes roi de France (888-898), Paris 1967 (Chart. et dipl. 11), Nr. 24, S. 103-113, hier S. 111; VONES-Liebenstein: Katalonien (wie Anm. 20), S. 499.

24 Ludwig VONES: Kardinal Rainer von San Clemente als päpstlicher Legat in Katalonien und Südwestfrankreich. Politische und diplomatische Aspekte, in: Aspects diplomatiques des voyages pontificaux, hg. v. Bernard BARBICHE/ Rolf Grosse, Paris 2009 (Studien und Dokumente zur Gallia Pontificia 6), S. 203-218, hier S. 206f. und DERS.: Das Papsttum und die Konstituierung einer katalanischen "Vorsprungslandschaft" im Grenzraum von Gallia und Hispania, in: Roma y la Península ibérica en la alta edad media. La construcción de espacios, normas y redes de relación - Rom und die Iberische Halbinsel im Hochmittelalter. Die Konstruktion von Räumen, Normen und Netzwerken, hg. v. Santiago Domínguez SÁnCHEZ/ Klaus Herbers, León/ Göttingen 2009, S. 157-171, bes. S. 166-168 und zuletzt Jonathan A. JARETT: Archbishop Ató of Osona. False metropolitans on the Marca Hispanica, in: ADipl 56 (2010) S. 142 . 
chen, blieb ohne nachhaltige Wirkung. Erst die Reconquista von Tarragona sollte den Stein wieder ins Rollen bringen.

Graf Berengar Raimund II. von Barcelona, der mit dem Beinamen el fratricida in die Geschichte einging, da er maßgeblich die Ermordung seines Zwillingsbruders Raimund Berengars II. Cap d'Estopes betrieben hatte ${ }^{25}$, um sich die Alleinherrschaft zu sichern, trug die Reconquista in den neunziger Jahren des 11. Jahrhunderts weit in den Camp de Tarragona vor, wenn auch die Stadt selbst immer noch in Trümmern lag. ${ }^{26}$ Mit einer Wiedererrichtung der Kirchenprovinz Tarragona bot sich ihm die Möglichkeit, seine Herrschaft gegenüber dem Widerstand der Partei seines verstorbenen Bruders abzusichern ${ }^{27}$, deren wichtigste Vertreter in der Cerdagne und der Grafschaft Carcassonne jenseits der Pyrenäen saßen und zu denen auch die Vizegrafen von Narbonne zählten, in deren Familie die Witwe des Cap d'Estopes eingeheiratet hatte. ${ }^{28}$

Die Wiedereroberung Tarragonas, verbunden mit einer Schenkung seines Herrschaftsbereiches an den Heiligen Stuhl ${ }^{29}$, schuf die materiellen und geisti-

$25 \mathrm{Zu}$ den Vorgängen um die Ermordung des Cap d'Estopes vgl. Próspero DE BOfARULL Y MASCARÓ: Los Condes de Barcelona vindicados, 2 Bde., Barcelona 1836, Bd. II, S. 115-124; Santiago SOBREQUÉS I VIDAL: Els grans comtes de Barcelona, Barcelona 1961, 2. Aufl. 1970, S. 143 ff.

26 Siehe zur Wiedereroberung Tarragonas immer noch Lawrence MCCRANK: La restauración canónica e intento de reconquista de la sede Tarraconense, 1076-1108, in: CHE 56-57 (1977/79) S. 145-245.

27 So schon Johannes FRIED: Der päpstliche Schutz für Laienfürsten. Die politische Geschichte des päpstlichen Schutzprivilegs für Laien (11.-13. Jh.), Heidelberg 1980 (AAH, Phil.-hist. Klasse, Jg. 1980, 1. Abh.), S. 87-97.

28 Vgl. auch Ursula VoneS-LiebenSTEIN: Saint-Ruf und Spanien. Studien zur Verbreitung und zum Wirken der Regularkanoniker von Saint-Ruf in Avignon auf der Iberischen Halbinsel (11. und 12. Jahrhundert), 2 Bde., Paris/ Turnhout 1996 (Bibliotheca Victorina VI), hier Bd. 1, S. 171-176; zu Mathilde d'Hauteville, der Tochter Robert Guiscards, siehe Szabolcs De VAjAY: Mahaut de Pouille, comtesse de Barcelone et vicomtesse de Narbonne, dans le contexte social de son temps, in: Béziers et le Biterrois. $43^{\text {e }}$ Congrès de la Fédération historique de Languedoc-Roussillon, Montpellier 1970, S. 129-150; Martin AURELL: Les noces du comte: mariage et pouvoir en Catalogne (785-1213), Paris 1995, S. 58 und 93; Manuel CASTEÑEIRAS: Le tapis de la création, Girona 2011, S. 89-94.

29 Paul KeHR: Das Papsttum und der Katalanische Prinzipat bis zur Vereinigung mit Aragon, Berlin 1926 (AAB, Phil.-hist. Klasse Nr. 15), S. 48; Odilo ENGELS: Schutzgedanke und Landesherrschaft im östlichen Pyrenäenraum (9.-13. Jahrhundert), Münster i. W. 1970 (SFGG 2. Reihe 14), S. 237f.; Alfons BECKER: La politique féodale d'Urbain II dans l'ouest et le sud de l'Europe, in: Droit privé et institutions régionales. Études historiques offertes à Jean Yver, Paris 1976, S. 43-56, hier S. 47 und 49; DERS.: Politique féodale de la papauté à l'égard des rois et des princes $\left(\mathrm{XI}^{\mathrm{e}}-\mathrm{XII}^{\mathrm{e}}\right.$ siècles), in: Chiesa e mondo feudale nei secoli X-XII. Atti della dodicesima Settimana internazionale di studio, Mendola, 24-28 agosto 1992, Mailand 1995 (Miscellanea del Centro di studi medioevali 14), S. 411-449, hier S. 434; MCCRANK: Restauración (wie Anm. 26), S. 185-188 sieht die Übertragung an Rom vor allem als Versuch Berengar Raimunds II., seinen Anspruch auf die maurischen Gebiete von Lérida und 
gen Voraussetzungen für eine Herauslösung der katalanischen Bistümer aus dem Metropolitanverband von Narbonne. Der Bischof von Ausona-Vic schien wie schon 100 Jahre zuvor geeignet, bis zur endgültigen Restitution des Metropolitansitzes dessen Verwaltung in Personalunion zu übernehmen. So teilte denn Urban II. 1089 allen proceres der Provinzen Tarragona und Barcelona unter namentlicher Nennung Graf Berengar Raimunds II. selbst sowie seiner Verbündeten Ermengold IV. von Urgell und Bernhard II. von Besalú - mit ${ }^{30}$, er sei zu einer Restauration der Kirchenprovinz Tarragona unter Bischof Berengar Seniofred von Vic bereit, salva tamen Narbonensis Ecclesiae justitia ${ }^{31}$.

Dieser Hinweis auf die Rechte der Kirche von Narbonne zeigt, wie wichtig die Wahrung bestehender Rechte für die Kurie war. Erzbischof Dalmatius von Narbonne, ein eifriger Verfechter der Kirchenreform, der von Anfang an in scharfem Gegensatz zu Berengar Raimund II. gestanden hatte ${ }^{32}$ und Bischof Berengar Seniofred von Vic sogar auf der Heimreise von einem Besuch ad limina einige Zeit gefangenhielt ${ }^{33}$, konnte jedoch seinen kanonischen Anspruch auf die Kirchenprovinz Tarragona durch die Vorlage päpstlicher Privilegien nicht erhärten. Dies zeigte sich, als der Kardinallegat Rainer von San Clemente, der spätere Paschalis II., zur Klärung der Frage ins Languedoc geschickt wurde. ${ }^{34}$ Folglich restituierte Papst Urban II. der Kirchenprovinz Tarragona alle ihre Rechte ${ }^{35}$, übertrug die Metropolitangewalt über die Tarraconensis dem Bischof von Vic und die Primatialgewalt über die Tarraconensis ebenso wie über die Narbonnensis dem Erzbischof Bernhard von Toledo ${ }^{36}$, in Übereinstimmung mit den ehemaligen westgotischen Kirchenstrukturen. Obwohl Berengar Raimund II. damit sein Ziel erreicht hatte, kam diese Lösung für ihn zu spät. Als sich auch König Alfons VI. von Kastilien auf die Seite seiner Geg-

Tortosa gegenüber Kastilien durch das Papsttum absichern zu lassen, verbunden mit der Absicht, den Primat Toledos abzuschütteln. Vgl. VONES: Kardinal Rainer (wie Anm. 24), S. 204f., der in Anm. 4 genau auf die Überlieferungslage der Schenkungsurkunde eingeht, sowie S. 214.

30 JL. 5401; MPL 151, Sp. 302f., Nr. 20; Ed.: Díplomatari de la catedral de Vic, segles IX-X, hg. v. Eduard JUNYENT I SUBIRA, Vic 1980, S. 838-840, Nr. 1554 I.

31 MPL 151, Sp. 303; Díplomatari Vic (wie Anm. 30), S. 840.

32 Ursula Vones-Liebenstein: Katalonien (wie Anm. 20), S. 166, 193.

33 So MCCRAnK: Restauración (wie Anm. 26), S. 216 und Josep Maria Martí Bonet: Roma y las Iglesias particulares en la concesión del palio a los obispos y arzobispos de occidente, Barcelona 1976, S. 208 f.

34 Vgl. die ausfuihrliche Darstellung der Ereignisse bei VONES: Kardinal Rainer (wie Anm. 24), S. 208-217.

35 Si enim Romani auctoritate privilegii Tarraconensem provinciam canonice vindicare Narbonensis antistes nequiverit (MPL 151, Nr. 20, Sp. 303; Díplomatari Vic (wie Anm. 30), S. 840).

36 Fidel FitA: Bula inédita de Urbano II, in: Boletín de la Real Academia de la Historia 5 (1884) S. 97f.; VONES: Kardinal Rainer (wie Anm. 24), S. 216. 
ner stellte, mußte er zur Sühne eine Pilgerreise ins Heilige Land antreten, von der er nicht mehr zurückkehrte. ${ }^{37}$

Sein Neffe und Nachfolger Raimund Berengar III. aber erklärte all seine Rechtsakte für ungültig und erneuerte die Schenkung von Tarragona an den Heiligen Stuhl nicht. ${ }^{38}$ Die Idee einer Restauration der Kirchenprovinz griff er jedoch auf ${ }^{\beta 9}$, nur daß diesmal die Verbindung zwischen kirchlichem und weltlichem Machtzentrum noch deutlicher wurde: Neuer Erzbischof von Tarragona wurde in Personalunion der Bischof von Barcelona und enge Mitarbeiter des Grafen, Ollegar Bonestruga. ${ }^{40}$ Für eine Verlegung des kirchlichen Mittelpunkts der Herrschaft von Barcelona nach Tarragona, wie dies im Nordwesten Spaniens im 8. Jahrhundert noch durch die Transferierung der Königsresidenz von León nach Oviedo der Fall gewesen war $^{41}$, war es allerdings zu spät.

So sollte die endgültige Loslösung von Narbonne erst Mitte des 12. Jahrhunderts vollzogen werden, nachdem Lucius II. ${ }^{42}$ und Eugen III. ${ }^{43}$ den Erzbi-

37 Bofarull y Mascaró: Los Condes (wie Anm. 25), Bd. II, S. 137-141, mit Verweis auf den Nekrolog von Santa Maria in Ripoll, wo zum 20. Juni verzeichnet ist: Berengarius comes Barchinonesis qui obiit in Ierhosolimam (ed. Eduard JUNYENT: El necrologi del monestir de Ripoll, in: Analecta Montserratensia IX [1962] S. 217-225 [= Miscellània Anselm M. Albareda], und Neudr. in DERS.: Estudis d'Història i Art [segles IX-XX], Vic 2001, S. 291-299, hier S. 296).

38 So wenn er am 26. Oktober 1099 bei der Schenkung von Sant Llorenç del Munt an Sant Cugat unterstreicht, $-\mathrm{da} a$ die vorhergehende Schenkung von Sant Llorenç an Saint-Pons de Thomières null und nichtig sein soll: Donum autem illud, quod a fratricida Berengario post parricidium Tomeriensi abbati inde dicitur esse factum, justicie obvium, condempnatione dignum, meo meorumque nobilium generali iuditio habentur semper irritum (Cartulario de San Cugat del Vallés, 3 Bde., hg. v. Joseph Rius SERRA, Barcelona 1945-1947, hier Bd. II, S. 435f., Nr. 777, Zitat S. 436). Vgl. auch FRIED: Der päpstliche Schutz (wie Anm. 27), S. 94 und Anm. 29, mit Verweis auf die ältere Literatur.

39 Lawrence MCCRANK: The foundation of the confraternity of Tarragona by Archbishop Oleguer Bonestruga, 1126-1129, in: Viator 9 (1978) S. 157-177, und DERS.: Norman crusaders in the Catalan reconquest: Robert Burdet and the principality of Tarragona, 1129-1155, in: Journal of Medieval History 7 (1981) S. 67-82. Siehe auch FRIED: Der päpstliche Schutz (wie Anm. 27), S. 97-101.

$40 \mathrm{Zu}$ Person und Laufbahn Ollegars, der vom Propst des Kathedralkapitels von Barcelona, Prior des Regularstifts Sant Adrià de Besòs und Abt von Saint-Ruf in Avignon zum Bischof von Barcelona und Erzbischof von Tarragona aufstieg, vgl. VONESLiEBENSTEIN: Saint-Ruf (wie Anm. 28), S. 194-209; Martin AuRELL: Prédication, croisade et religion civique. Vie et miracles de l'évêque Oleguer († 1137) de Barcelone, in: RevMab 71 (1999) S. 113-168; und zuletzt Josep Maria MARTí BONET/ Anna RICH ABAD/ Joan BELLÈs: Oleguer, servent de les esglésies de Barcelona i Tarragona, Barcelona 2003.

41 Fernando LÓPEZ AlsinA: El encuadramiento eclesiástico como espacio de poder: de la parroquía al obispado, in: Los espacios de poder en la España medieval. XII Semana de Estudios Medievales, Logroño 2001, S. 425-457, bes. S. 429f.

42 Paul Fridolin KeHR: Papsturkunden in Spanien. Vorarbeiten zur Hispania Pontificia I. Katalanien, Berlin 1926 (AGG, Phil.-hist. Klasse NF XVIII,2), Bd. I, S. 320-322, 
schöfen von Tarragona das Recht verliehen hatten, Suffraganbischöfe zu ordinieren, Konzilien abzuhalten und omnia iuxta metropolitani curam ... prouidere. Anastasius IV. bestätigte schließlich Erzbischof Bernhard Tort alle elf Suffraganbistümer von Tarragona, darunter auch die vier altkatalanischen von Girona, Barcelona, Urgell und $\mathrm{Vic}^{44}$, und betonte, ipsi tamquam sue metropoli subditas esse decernimus ${ }^{45}$.

Von den fünf katalanischen Bistümern war einzig Elne der neuen Metropole Tarragona nicht unterstellt worden. Dafür sprachen sowohl kirchenpolitische als auch weltliche Gründe. Das in westgotischer Zeit bezeugte Bistum Elne - erstmals wurde 571 ein Bischof erwähnt - entsprach von seinen Grenzen her, welche die pagi Roussillon, Vallespir und Conflent einschlossen ${ }^{46}$, der römischen civitas Ruscinonensis. ${ }^{47}$ Seine Bischöfe sind in westgotischer Zeit als Teilnehmer an den Konzilien von Toledo bezeugt ${ }^{48}$, seit der Wiedererrichtung des Bistums in fränkischer Zeit nahmen sie an den Synoden in Narbonne teil. ${ }^{49}$

Was die politische Lage betrifft, so herrschte zur Zeit der Wiedererrichtung der Metropole Tarragona Ende des 11. Jahrhunderts Graf Gislabert II. (1074-1102) im Roussillon, der 1074 und 1085 ein enges Bündnis mit den Grafen von Empurien schlo $\beta^{50}$, jedoch offensichtlich keine guten Beziehungen $\mathrm{zu}$ Berengar Raimund II. von Barcelona unterhielt. ${ }^{51}$ In den folgenden Jahrzehnten verfolgten die Grafen von Roussillon eine stärker auf das Languedoc

Nr. 53, 1144 März 25 für den vom Papst selbst konsekrierten Erzbischof von Tarragona, Abt Gregorius von Cuixà.

43 PU Katalanien I (wie Anm. 42), S. 322-324, Nr. 54, 1145 Mai 27 für Erzbischof Bernhard Tort von Tarragona.

44 PU Katalanien I (wie Anm. 42), S. 336-339, Nr. 65: episcopalium preterea cathedrarum urbes id est Gerundam, Barcinonam, Urgellum, Ausonam, Ilerdam, Dertosam, Caesaraugustam, Oscam, Pampilonam, Tirasonam et Calagorram für Erzbischof Bernhard Tort.

45 Ebd., S. 338.

46 In der Divisio Wambae wird dies folgendermaßen umschrieben: Elna teneat de Angera usque Rosinolam, de Latrosa usque Lamusam (VAZQUeZ DE PARGA: División [wie Anm. 19], S. 115).

47 Pere Ponsich: El Marc històric, in: El Rosselló, Barcelona 1993 (Catalunya Romànica XIV), S. 21-74, hier S. 27, der sich hier der Meinung von Bernard Alart, dem Archivar und Geschichtsschreiber der Diözese Elne im 19. Jahrhundert, anschließt.

48 Vives: Concilios (wie Anm. 14), S. 137 zum III. Toletanum 589; S. 222 zum IV. Toletanum 633; S. 246 zum VI. Toletanum 638; S. 433 zum XIII. Toletanum 683 entsandten sie nur jeweils einen Vertreter.

49 So beispielsweise 792 am Konzil von Narbonne (PONSICH: El Marc històric [wie Anm. 47], S. 35). Vgl. die Konzilsakten bei MANSI XIII, Sp. 821-824: totum Redensem pagum super Vvinedurium Helenensem episcopum justissime evindicavit (Sp. 822f.).

50 Pierre DE MARCA: Marca Hispanica sive Limes Hispanicus, hg. v. Étienne BAluze, Paris 1688, Neudr. Barcelona 1972, Sp. 1176f., Nr. 297, und L'Empordà I, Barcelona 1989 (Catalunya Romànica VIII), S. 72f., mit einer Übersetzung ins Katalanische von Joan BADIA I HOMS.

51 VONES-Liebenstein: Saint-Ruf (wie Anm. 28), S. 90. 
als auf Katalonien ausgerichtete Politik, wie die Heirat Graf Gausfreds III. (1121-1164) mit Ermengard, gen. Trencavella (1110-1152), der Tochter Vizegraf Bernhard Attons IV. von Béziers, zeigt. ${ }^{52}$ Erst als dieser 1152 Ermengard verstie $\beta$ und eine Frau heiratete, die in den Papstbriefen nur als adultera bezeichnet wird und deren Name ebensowenig überliefert ist wie der ihrer Kinder, wandte sich sein Sohn und Erbe Gerald II. (1164-1172) Katalonien zu und hinterließ seine Grafschaft Alfons II. von Aragón als Erbe. ${ }^{53} \mathrm{Zu}$ diesem Zeitpunkt waren jedoch die kirchlichen Verhältnisse bereits so festgeschrieben, daß an eine Angleichung zwischen kirchlichen und weltlichen Grenzen nicht mehr zu denken war.

\section{Die Grafschaft Melgueil und die Exemtion von Maguelonne}

Am anderen Ende der Kirchenprovinz Narbonne hatte Graf Peter von Melgueil oder Substantion 1085 eine ähnliche Entwicklung, wenn auch nicht im gleichen Umfang, in Gang gesetzt. Das Bistum Maguelonne war in westgotischer Zeit wie Uzès und Arisitum im letzten Drittel des 6. Jahrhunderts aus dem Bistum Nîmes ausgegliedert worden. ${ }^{54}$ Seine Bischöfe nahmen an den Konzilien in Toledo teil oder entsandten Stellvertreter ${ }^{55}$, bevor sie sich nach dem Anschluß Septimaniens ans Frankenreich auf fränkischen Synoden einfanden..$^{56}$ Mitte des 8. Jahrhunderts ist in Maguelonne der Vater eines gewissen Witiza, des späteren Benedikt von Aniane, als Graf bezeugt. ${ }^{57}$ Im Laufe des 9.

52 Hélène DebaX: La féodalité languedocienne, $\mathrm{XI}^{\mathrm{e}}-\mathrm{XII}{ }^{\mathrm{e}}$ siécles. Serments, hommages et fiefs dans le Languedoc des Trencavel, Toulouse 2003, S. 80, 89.

53 Pere PONSICH: El Marc històric (wie Anm. 47), S. 33 vermutet, daß der Grund für dieses Vermächtnis in der Besorgnis lag, die Söhne aus der zweiten Ehe seines Vaters könnten sich der Grafschaft bemächtigen. Vgl. das Testament bei MARCA: Marca Hispanica (wie Anm. 50), Sp. 1339, Nr. 443; Francisco MiQuel Rossell: Liber Feudorum major, 2 Bde., Barcelona 1945/46, Bd. II, S. 274-277, Nr. 792, und mit einer Übersetzung ins Katalanische in: PONSICH: El Marc històric (wie Anm. 47), S. 40f.

54 FÉvrier/ Barral i Altet: Topographie chrétienne (wie Anm. 14), S. 52; SCHneIDER: Cités (wie Anm. 12), S. 4 referiert die These, die Abspaltung der Bistümer Elne und Carcassonne von Narbonne und des Bistums Maguelonne von Nîmes habe während der Herrschaft des westgotischen Königs Liuva (567-572) stattgefunden, als Narbonne für kurze Zeit Königsresidenz war.

55 So am III. Toletanum 589 (VIVES: Concilios [wie Anm. 14], S. 138), am IV. Toletanum 633 (ebd., S. 225) und am XIII. Toletanum 683 (ebd., S. 432).

56 So auf der Synode von Narbonne 791 (MANSI XIII, Sp. 824) und auf dem Konzil von Châlon-sur-Saône 875 (MANSI XVII, Sp. 300).

57 SChNeIder: Cités (wie Anm. 12), S. 5. So heißt es in Ardos Vita Benedikts: Pater siquidem eius comitatum magdalonensem . quoadusque uiam tenuit. Vgl. die Neuedition und Übersetzung dieser Vita durch Walter KetTEMANN: Subsidia Anianensia. Überlieferungs- und textgeschichtliche Untersuchungen zur Geschichte Witiza-Benedikts, seines Klosters Aniane und zur sogenannten ,anianischen Reform“. Mit kommentierten 
Jahrhunderts wurde der Sitz der Grafschaft von Maguelonne nach Substantion, einem castrum an der Via Domitiana verlegt. ${ }^{58}$ Erst Ende des 11. Jahrhunderts nannten sich die Grafen dann nach dem Ort Mauguio oder Melgueil. ${ }^{59} 1085$ übertrug Graf Peter von Melgueil omnem honorem meum, tam comitatum Substantionensem quam episcopatum Magalonensem als Allod sanctae Romanae Ecclesiae, E sanctis apostolis Petro \& Paulo, necnon \& papae Gregorio VII \& omnibus successoribus ejus. Mit einem Ring übergab er seine Grafschaft und das Bistum an die Vertreter des Papstes, den Kardinallegaten Petrus von Albano, Bischof Gottfried von Maguelonne und Abt Frotard von Saint-Pons de Thomières, mit der Maßgabe, sein Sohn und Nachfolger Raimund solle künftig die Grafschaft per manum Romani pontificis ad fidelitatem illius besitzen. ${ }^{60}$

Die Gründe für diese Schenkung liegen nicht auf der Hand. Wollte er sich damit gegen seine immer mächtiger werdenden Vasallen, die Wilhelme von Montpellier, absichern, denen er dennoch eine seiner Töchter zur Heirat gegeben hatte? ${ }^{61}$ War er restlos verschuldet, wie aus mehreren Transaktionen der Jahre zuvor mit dem Kapitel von Maguelonne hervorgeht? ${ }^{62}$ Oder war es tat-

Editionen der ,Vita Benedicti Anianensis', ,Notitia de servitio monasteriorum', des ,Chronicon Moissiacense/ Anianense' sowie zweier Lokaltraditionen aus Aniane, Teil I, Diss. phil. Duisburg 2000 (URL: http://duepublico.uni-duisburg-essen.de/ servlets/DocumentServlet?id=18245), S. 143.

58 SCHNEIDER: Cités (wie Anm. 12), S. 5.

59 Laurent SCHNEIDER: In regno Septimanie, in comitatu et territorio biterrensi. Le Biterrois et l'aristocratie biterroise de la fin du IX ${ }^{\mathrm{e}}$ s. à la fin du X $\mathrm{X}^{\mathrm{e}}$ s., in: AM 119 (2007) S. 409456, hier Anm. 70, mit weiterführenden Literaturangaben. Zur Geschichte der Grafen von Melgueil siehe immer noch Alexandre GERMAIN: Étude historique sur les comtes de Maguelone, de Substantion et de Melgueil, in: Mémoires de la Société archéologique de Montpellier 3 (1850-1854) S. 523-622.

60 Claude DeVic/ Joseph VAisseTE: Histoire Générale du Languedoc avec des notes et des pièces justificatives, 16 Bde, 2. Aufl. Toulouse 1876-1892, künftig zitiert als HGL, hier HGL V, Nr. 365, Sp. 695f.; Julien RouQuetTe/ Augustin Villemagne: Cartulaire de Maguelone, Bd. I, Montpellier 1912, Nr. XIV, S. 18-20. Siehe dazu GERMAIN: Étude historique (wie Anm. 59), S. 536-539; Georges BEAUME: Maguelone, unique fief pontificale en terre de France, in: Revue des études historiques 81 (1915) S. 467-485; ENGELS: Schutzgedanke (wie Anm. 29), S. 238-240; FRIED: Der päpstliche Schutz (wie Anm. 27), S. 72-74; Alfons BECKER: Papst Urban II. (10881099), 2 Bde., Stuttgart 1964-1988 (MGH Schr. 19), Bd. I, S. 206-209; DERS.: Politique féodale de la papauté (wie Anm. 29), S. 420 und 430.

$61 \mathrm{Zu}$ den Herren von Montpellier und ihrem Aufstieg siehe Archibald Ross LEWIS: The Guillems of Montpellier: A Sociological Appraisal, in: Viator 2 (1972) S. 159-170; DERS.: Seigneurial Administration in Twelfth Century Montpellier, in: Speculum 22 (1947) S. 562-577, sowie Hideyuki KATSURA: Serments, hommages et fiefs dans la seigneurie des Guilhem de Montpellier (fin XI' -début XIII siècle), in: AM 104 (1992) S. $141-161$.

62 Siehe die Urkunden im Cartulaire de Maguelone (wie Anm. 60), S. 13f., Nr. X (1079 Juli 23), S. 15, Nr. XI (1079 Aug. 9), S. 16, Nr. XII (1060-1080), S. 17, Nr. XIII (1083 Jan.). 
sächlich die Sorge um sein Seelenheil und der Wunsch, wie wenige Jahre später sein Schwager Raimund von Saint-Gilles als miles sancti Petri zu sterben? ${ }^{63}$

Sein Sohn und Nachfolger Raimund, der die Schenkungsurkunde ebenso wie seine Mutter Almodis von Toulouse unterzeichnet hatte ${ }^{64}$, war zunächst keineswegs bereit, das Testament seines Vaters anzuerkennen. Bischof Gottfried von Maguelonne, der die Entscheidung Graf Peters wohl mit beeinflußt hatte $^{65}$, exkommunizierte den jungen Grafen daraufhin. Beide trugen den Fall an der Kurie vor, an die sich der Graf mit einem Gefolge von zahlreichen Adligen begeben hatte. ${ }^{66}$ Dort wurde entschieden, daß die Verfügung seines Vaters rechtmäßig sei, woraufhin er die Grafschaft Melgueil von Urban II. zu Lehen nahm, gegen das Versprechen, jährlich ein Pfund Gold als Zins nach Rom abzuführen und alsbald zu einer Pilgerfahrt nach Santiago de Compostela aufzubrechen. ${ }^{67}$ Urban II. übertrug das Recht zur Einsetzung des Grafen an den Bischof von Maguelonne, jedoch schweigen die Quellen zu der Frage, wie dies in den folgenden Jahrzehnten gehandhabt wurde.

Wichtiger ist in unserem Zusammenhang die Tatsache, daß Graf Peter zusammen mit der Grafschaft auch das Bistum an den Papst übertragen hatte, das er ebenfalls als sein Allod bezeichnete. Gerade durch den ausdrücklichen Ver-

63 Zur Bedeutung dieses Titels siehe BECKER: Politique féodale de la papauté (wie Anm. 29), S. 420, 424-426, 430; zu Raimund von Saint-Gilles siehe Ursula VONESLiEBENSTEIN: L'abbaye de Saint-Gilles et les comtes de Toulouse. L'impact des voyages pontificaux en France, in: Aspects diplomatiques (wie Anm. 24), S. 97-116, bes. S. 110-113.

64 Cartulaire de Maguelone (wie Anm. 60), Nr. XIV: Adalmodis comitissa firmavit ... Raimundus comes filius ejus firmavit. Isti omnes ex precepto comitis firmaverunt ante altare beati Petri (S. 20).

65 Dafür spricht sowohl der Passus über die Freiheit der Bischofswahl von laikalen Einflüssen als auch die Tatsache, daß er neben dem Kardinallegaten und dem Abt von Thomières unter jenen genannt wurde, in deren Hand der Graf die Schenkung tätigte. $\mathrm{Zu}$ Gottfried, einem eifrigen Vertreter der Kirchenreform, der von Erzbischof Dalmatius von Narbonne konsekriert worden war, vgl. Honoré FISQUET: La France pontificale (Gallia christiana). Histoire chronologique et biographique des archevèques et évéques de tous les diocèses de France, 22 Bde., Paris 1864-1873, hier Bd. 4: Diocèse de Maguelone, S. 54-60; Elisabeth MAGNOU-NORTIER: La Société laïque et l'Église dans la province ecclésiastique de Narbonne de la fin du $\mathrm{VIII}^{\mathrm{e}}$ à la fin du $\mathrm{XI}^{\mathrm{e}}$ siècle, Toulouse 1974, S. 530, 561; Vones-Liebenstein: Saint-Ruf (wie Anm. 28), S. 102.

66 HGL V, Sp. 760, Nr. 404; Cartulaire de Maguelone (wie Anm. 60), S. 31f., Nr. XX: episcopus [sc. Gottfried] ivit Romam. Et non multo post comes Raimundus eum secutus est. Quumque ambo dominum Papam Urbanum II adiissent [...]. In Begleitung Raimunds befinden sich acht Adelige, darunter Dalmatius von Castries, Wilhelm von Vallauquès, Wilhelm von Valmalle und Bertrand von Saint-Nazaire. Siehe auch GERMAIN: Étude historique (wie Anm. 59), S. 542.

67 HGL V, Sp. 761, Nr. 404; Cartulaire de Maguelone (wie Anm. 60), S. 32, Nr. XX; siehe auch Theodor SCHIEFFER: Die päpstlichen Legaten in Frankreich: vom Vertrage von Meersen (870) bis zum Schisma von 1130, Berlin 1935 (Historische Studien 263), S. $138 f$. 
zicht, künftig Einfluß auf die Bischofswahl zu nehmen ${ }^{68}$, schloß er auch den Einfluß Dritter aus und erfüllte so geradezu vorbildlich die Forderungen der Kirchenreformer. Zwar betonte Urban II. in seinem Privileg, das Bistum stehe fortan besonders sub Romana libertate ${ }^{69}$, nahm jedoch die Metropolitanrechte von Narbonne bezüglich der Bischofsweihe davon ausdrücklich aus: salva Narbonensis metropolitani auctoritate ac reverentia ${ }^{70}$, mit der nicht ungewöhnlichen Einschränkung, der Erzbischof von Narbonne müsse gute Beziehungen zu Rom unterhalten. ${ }^{71}$

Gehörte Maguelonne also auch weiterhin dem Metropolitanverband von Narbonne an? Zumindest war im 12. Jahrhundert bekannt, daß es in westgotischer Zeit dazugehört hatte, da sich eine der verschiedenen Redaktionen der Divisio Wambae im 12. Jahrhundert dort befand. ${ }^{72}$ Trotzdem nahm Maguelon-

68 Sit vero in potestate Romani pontificis in episcopatu Magalonensi quem placuerit episcopum juste et canonice ordinare, et per eum et auctoritatem eius liceat Magalonensi ecclesie juxta constitutiones et decreta sanctorum Patrum personam probabilem et idoneam ad regendum populum et res ecclesiasticas; liceat, inquam, et ex hoc deinceps probabilem et idoneam personam in episcopatu eligere, absque mei vel alicujus heredum aut successorum meorum contradictione (Cartulaire de Maguelone [wie Anm. 60], S. 18, Nr. XIV; HGL V, Sp. 695f., Nr. 365, wo der Text verschiedentlich, wenn auch nicht wesentlich abweicht).

69 JL. 5375 von 1088 Dez. 14; MPL 151, Sp. 293f., hier 294; Julien RouQuetTe/ Alexandre de Villemagne: Bullaire de l'église de Maguelone (1030-1216), Bd. I, Montpellier 1911, S. 6-15, Nr. 4, mit einem ausführlichen Kommentar, hier S. 7.

70 Zur Salva-Formel siehe Georg SCHREIBER: Kurie und Kloster im 12. Jahrhundert, Stuttgart 1910 (Kirchenrechtliche Abhandlungen 65/66, 67/68), S. 56-63, der im Hinblick auf die exemte Stellung von Klöstern betont, daß der Vorbehalt bischöflicher Rechte bis zur Mitte des 12. Jahrhunderts vor allem für nicht exemte Klöster verwendet wurde. Analog könnte man hier schließen, daß Maguelonne zur Zeit Urbans II. noch nicht aus dem Metropolitanverband von Narbonne gelöst war.

$71[\ldots]$ siquidem legitime ordinatus fuerit, et quamdiu communionem Apostolice Sedis habuerit; quod si nequaquam talis extiterit, ad Romanum Pontificem Magalonensis electus consecrandus accedat (Bullaire Maguelone [wie Anm. 69], S. 8, Nr. 4). Angesichts der Tatsache, daß sich in Narbonne der Kandidat des Papstes, Dalmatius von La Grasse, über vier Jahre lang gegen den Bruder des Vizegrafen, Bischof Peter Berengar von Rodez, nicht hatte durchsetzen können, ist die Tendenz des Papsttums unverkennbar, Einfluß auf Bischofswahlen im Languedoc zu nehmen. Siehe in diesem Sinne Ursula VONESLiEBENSTEIN: Zentrum und Peripherie? Das universale Papsttum und die Kirchenprovinz Narbonne im Hochmittelalter: 1050-1215, in: Rom und die Regionen, hg. v. Jochen JOHRENDT/ Harald MÜLlER, Göttingen 2012 (AAG NF 19), S. 209-248, hier S. 221-224.

72 Vazquez de Parga: División (wie Anm. 19), S. 45, zitiert ein Schreiben der Bischöfe von Tarazona, Salamanca und Porto an Papst Lucius III. bezüglich des Streites zwischen Braga und Compostela um den Besitz der Bistümer Coimbra, Viseu, Lamego und Idanha, in dem von einer Version der Divisio die Rede ist, die sich in einem instrumentum quoddam bullatum de Magalonensi ecclesia fand, das heute leider verschollen ist (vgl. ebd., S. 53). Die Zugehörigkeit zur Narbonnensis wird auch in den anderen Redaktionen der Divisio bezeugt (S. 108, 115, 118 und 127), wie auch die Grenzen Ma- 
ne seit der Schenkung Graf Peters eine Sonderstellung ein: Sein Bischof fungierte wie der von Burgos immer wieder in Stellvertretung des Papstes ${ }^{73}$, die Päpste selbst hielten sich vermehrt dort auf, wenn sie gallischen Boden betra$\operatorname{ten}^{74}$, und der Bischof von Maguelonne war neben dem Erzbischof von Narbonne der einzige, der als päpstlicher Legat im Languedoc fungierte. ${ }^{75} \mathrm{Als} 1215$ den Grafen von Toulouse als Erben und Rechtsnachfolgern der Grafen von Melgueil der Besitz der Grafschaft aberkannt wurde ${ }^{76}$, übertrug sie Innocenz III. an den Bischof von Maguelonne. ${ }^{77}$ Die von Graf Peter gewünschte Kongruenz weltlicher und kirchlicher Grenzen unter dem Schutz des heiligen Petrus war damit vollzogen.

\section{Narbona metropolis: die unmögliche Einheit}

Anders als die Grafen von Barcelona, denen sich durch die Rückeroberung der Metropole Tarragona die Möglichkeit geboten hatte, kirchliche und weltliche Grenzen in Einklang zu bringen und selbst die durch günstige Erbfälle und

guelonnes angeführt werden: Magalona teneat de Mirla usque Ribogar, de Castel milan usque Angoram (S. 84, Nr. 68).

73 So schrieb Paschalis II. 1100 den spanischen Bischöfen, er habe den Bischof von Maguelonne mit der Weihe des Bischofs von Compostela beauftragt. Sollte dieser dies ablehnen, so sollte die Weihe vom Bischof von Burgos qui nostri juris est vollzogen werden (JL. 5839; MPL 163, Sp. 45, Nr. 25; Bullaire Maguelone [wie Anm. 69], Bd. I, S. 26f., Nr. 11, hier S. 27; Historia Compostellana, hg. v. EMma FalqUE, Turnhout 1988 [CChrCM LXX], S. 24f.). In einem weiteren Schreiben forderte er ihn erneut auf : electum ipsum vice nostra in episcopum zu weihen (JL. 5860; MPL 163, Sp. 63, Nr. 41; Bullaire Maguelone [wie Anm. 69], S. 27, Nr. 12; Historia Compostellana [wie hiervor], S. 25).

74 Angeführt seien hier nur Urban II., der 1096 fünf Tage in Maguelonne blieb und dort die Insel, auf der sich Kathedrale und Stiftsimmunität befanden, weihte (Bullaire Maguelone [wie Anm. 69], S. 24f., Nr. 8); Gelasius II., der im November 1119 mehrere Tage in Maguelonne verbrachte (Bullaire Maguelone [wie Anm. 69], S. 31f., Nr. 15); Calixt II., der im Juni 1119 zehn Tage dort weilte (ebd., S. 35, Nr. 16); und Alexander III., der auf seiner Flucht nach Frankreich zuerst in Maguelonne blieb und den Hauptaltar der Domkirche weihte. Siehe auch GERMAIN: Étude historique (wie Anm. 59), S. 545f.; VONES-LIEBENSTEIN: Zentrum (wie Anm. 71), S. $226 f$.

75 So führte Bischof Walter von Maguelonne den Titel eines päpstlichen Legaten (SCHIEFFER: Die päpstlichen Legaten [wie Anm. 67], S. 226).

76 Am 14. April 1215 (MPL 217, Sp. 249, Nr. 209), siehe Daniel Le Blevec/ Thomas GARNIER: L'évêché de Maguelone au Moyen Age: actes de la journée d'études du 13 décembre 2001, Montpellier 2005 (Monspeliensia medievalia 2).

77 Zum Fortbestand der auf der Schenkung Graf Peters begründeten päpstlichen Rechte über die Grafschaft Melgueil und das Bistum Maguelonne im 13. Jahrhundert siehe Julien Rouquette: Saint-Louis et le comté de Melgueil, in: RHEF 5 (1914) S. 182199. 
glückliche Heiraten ${ }^{78}$ erworbenen Herrschaften - mit Ausnahme der Grafschaften Carcassonne, Roussillon und Provence, deren letztere schließlich an eine Sekundogenitur fiel und durch Heirat an das kapetingische Haus Anjou kam - in diese Grenzen einzubinden, war es in Septimanien den Grafen von Toulouse im ausgehenden 11. und zu Beginn des 12. Jahrhunderts nicht vergönnt, eine einheitliche kirchliche Klammer für ihr disparates Herrschaftsgebiet zu finden.

Sahen sie sich im 10. und der ersten Hälfte des 11. Jahrhunderts noch mit den Interessen der Wilhelmidischen Grafen von Carcassonne konfrontiert ${ }^{79}$, so wurden diese seit der Mitte des 11. Jahrhunderts durch die Herzöge von Aqui$\operatorname{tanien}^{80}$, die Grafen von Barcelona ${ }^{81}$ und die Trencavel, Vizegrafen von Béziers, Nîmes, Agde und Albi, abgelöst ${ }^{82}$, die die Ausbildung eines territorial zusammenhängenden Herrschaftsgebietes der Raimunde von Toulouse verhinderten. Diese mußten sich immer wieder gegen konkurrierende Adlige im ,eigenen Haus` verteidigen, die bei Bedarf das Bündnis mit Barcelona suchten, von den Trencavel über die Vizegrafen von Narbonne bis hin zu den Herren von Montpellier. Zwar sollte es auch den verschiedenen vizegräflichen Familien vor allem wegen fehlender Rechtstitel nicht gelingen, in ihren eigenen

78 Man denke nur an die Heirat Raimund Berengars IV. mit der Erbtochter des Königreiches Aragón, Petronilla. Siehe dazu Antonio Ubieto ARTEta: Los esponsales de la reina Petronila y la creación de la corona de Aragón, Saragossa 1987, und AUrelL: Les Noces (wie Anm. 28), S. 361-380, 410f., 476.

79 Christian LAURANSON-ROZAS: Les Guillelmides: une famille de l'aristocratie d'empire carolingienne dans le Midi de la Gaule (VIII ${ }^{\mathrm{e}}-\mathrm{X}^{\mathrm{e}}$ siècles), in: Entre histoire et épopée. Les Guillaume d'Orange (IX ${ }^{\mathrm{e}}-\mathrm{XIII}{ }^{\mathrm{e}}$ siècles). Hommage à Claudie Amado, hg. v. Laurent MACE, Toulouse 2006, S. 45-81, und Hélène DEBAX/ Franck PONTIES: Saint Hilaire, saint Saturnin et Roger. Un réseau guilhelmide dans le comté de Carcassonne au $\mathrm{X}^{\mathrm{e}}$ siècle, ebd., S. 117-133.

$80 \mathrm{Zu}$ den Ansprüchen der Philippa von Toulouse auf die Nachfolge ihres Vaters, des Grafen Wilhelm IV. von Toulouse, siehe Walther KIENAST: Der Herzogstitel in Frankreich und Deutschland (9.-12. Jahrhundert), München/ Wien 1968, S. 230; VONES-LiebenSTEIN: L'abbaye de Saint-Gilles (wie Anm. 63), S. 106-108 mit weiterführender Literatur. Da Philippa diese Ansprüche auf ihren Sohn Wilhelm X. von Aquitanien vererbte, von dem sie auf dessen Tochter Eleonore von Aquitanien weitergingen, zogen sich die Auseinandersetzungen um den Besitz von Toulouse bis zum Ende des 12. Jahrhunderts hin.

81 Vgl. zum Übergang der Grafschaft Carcassonne auf das Grafenhaus von Barcelona ENGELS: Schutzgedanke (wie Anm. 29), S. 113f., 257; Fredric L. ChEYeTtE: The „Sale“ of Carcassonne to the Counts of Barcelona (1067-1070) and the Rise of the Trencavels, in: Speculum 63 (1988) S. 826-864; DÉBAX: Féodalité (wie Anm. 52), S. 58-71; Hélène DÉBAX: Les comtés de Carcassonne et de Razès et leurs marges (IX ${ }^{\mathrm{e}}-\mathrm{XII}{ }^{\mathrm{e}}$ siècles). Introduction historique, in: France méridionale, Espagne. Histoire des Sociétés du Moyen Age à l'époque contemporaine, Toulouse 2007, S. 1-17, bes. S. 8 f.

82 Zum Erwerb der sechs Vizegrafschaften - zu denen noch das Razès und Carcassonne zählten - und ihrem unter Bernhard Atton IV. vollendeten Herrschaftsausbau siehe DÉBAX: Féodalité (wie Anm. 52), S. 270-285. 
Gebieten eine Stabilisierung durch die Übereinstimmung von weltlichen und geistlichen Grenzen zu erreichen ${ }^{83}$, jedoch wirkte sich dies letztlich nicht zugunsten der Grafen von Toulouse aus.

Hinzu kam noch, daß der Metropolitansitz von Narbonne im Einflußbereich der Vizegrafen dieser Stadt lag, die seit der Heirat der Witwe Raimund Berengars II. von Barcelona mit Vizegraf Aimerich von Narbonne auf seiten der Katalanen standen. ${ }^{84}$ Andererseits erstreckten sich die Besitzungen der Grafen von Toulouse auch auf die Territorien von sechs Metropolitansitzen, wie aus der Erklärung Raimunds VI. vom 19. Juni 1209 in Saint-Gilles hervorgeht, wo er auf alle seine Rechte über die Bistümer in den Kirchenprovinzen Narbonne, Bourges, Auch, Arles, Vienne und Bordeaux ebenso verzichtete wie auf Spolienrechte, das Recht, im Fall einer Vakanz die Einkünfte einzuziehen, und das Recht, Einfluß auf die Bischofswahlen zu nehmen. ${ }^{85}$

83 So beruhte beispielsweise die Machtgrundlage der Trencavel auf einem Netzwerk von Lehensbeziehungen, das ihnen Zugang zu den wichtigsten Burgen ihres Herrschaftsgebietes sicherte (DÉBAX: Féodalité [wie Anm. 52], S. 273; DÉBAX: Comtés de Carcassonne [wie Anm. 81], S. 10f., 13-15), ohne ihnen jedoch Anspruch auf eine Einflußnahme auf den Episkopat zu garantieren. War es im 11. Jahrhundert noch üblich gewesen, daß jüngere Söhne aus vizegräflichen Familien, wie z. B. in Nîmes Frotard I., 987-1016, und Frotard II., 1027-1077, die Bischofsstühle besetzten (KAISER: Bischofsherrschaft [wie Anm. 14], S. 319f.), so wurde dies seit der Kirchenreformbewegung immer schwieriger. In Albi hatte der Vizegraf das Bistum und die Bischofswahl vom Grafen zu Lehen erhalten, mußte seine Rechte jedoch 1194 mit dem Bischof teilen (DÉBAX: Féodalité [wie Anm. 52], S. 272, bes. Anm. 16); in Béziers kam es wiederholt zu erbitterten Auseinandersetzungen, die der Tolosaner Graf für sich zu nutzen suchte (Henri VIDAL: Episcopatus et pouvoir épiscopal à Béziers à la veille de la Croisade Albigeoise, 1152-1209, Montpellier 1951; Claudie AmADO: Les vicomtes de Béziers et d'Agde. Déploiement lignager et bipolarité du pouvoir, in: Vicomtes et vicomtés dans l'Occident médiéval, hg. v. Hélène DÉBAX, Toulouse 2008, S. 21-31); und in Agde übertrug der Vizegraf sogar aus einer Notsituation heraus 1187 all seine Rechte auf den Bischof (DÉBAX: Féodalité [wie Anm. 52], S. 279f.; Pierre CHASTANG: La donation de la vicomté d'Agde (1187) ou les vicissitudes du vicecomitatus aux XII ${ }^{\mathrm{e}}$ et XIII ${ }^{\mathrm{e}}$ siècle, in: Vicomtes et vicomtés, S. 33-45). Zum Ausbau bischöflicher Macht in den Machtzentren der Trencavel siehe auch KAISER: Bischofsherrschaft (wie Anm. 14), S. 283-320.

84 Nachdem noch Raimund von Saint-Gilles gute Beziehungen zu Erzbischof Wifred (1019-1079) unterhalten hatte, trotzdem dieser von Gregor VII. exkommuniziert worden war. Die Erzbischöfe der ersten Hälfte des 12. Jahrhunderts wiederum waren eng verwandt mit der Familie der Vizegrafen von Narbonne (Richard von Millau, 11061121, Arnald von Lévezou, 1121-1149, und Berengar von Narbonne, 1156-1162), bevor mit Berengar von Barcelona ein illegitimer Sohn Raimund Berengars IV. von Barcelona Metropolit von Narbonne wurde (1191-1212). Vgl. zu diesen Verwandtschaftsverhältnissen Jacqueline CAILlE: Vicomtes et vicomté de Narbonne, in: Vicomtes et vicomtés (wie Anm. 83), S. 47-60 und die Genealogie auf der beiliegenden CD S. 47.

85 Siehe den Druck der Urkunde bei MPL 216, Sp. 93f., Nr. 6: omnibus ecclesiis et domibus religiosis provinciarum Viennensis, Arelatensis, Narbonensis, Auxitanensis, Burdegalensis, et Bi- 
War es den Grafen von Barcelona und Melgueil gelungen, durch eine Übertragung ihres Herrschaftsbereiches an den Papst diesen für ihre Pläne zu gewinnen, so legte Raimund von Saint-Gilles durch die Übernahme des Titels eines Herzogs von Narbonne ${ }^{86}$ zwar die Grundlage für eine enge Beziehung zwischen dem Metropolitansitz und dem Grafenhaus, suchte jedoch nur für sich persönlich die Anbindung an das Papsttum, um eine führende Rolle in dem von Urban II. propagierten Kreuzzug ins Heilige Land zu spielen. ${ }^{87}$ Die Grafschaft Toulouse wie auch seine Besitzungen in der Provence übertrug er zuvor an seinen Sohn Bertrand ${ }^{88}$, der weder den Titel eines Herzogs von Narbonne führte noch die Grafschaft Toulouse gegenüber den Aquitaniern effektiv verteidigen konnte. ${ }^{89} \mathrm{Nach}$ dem Tod seines Vaters und der Rückkehr seines kleinen Stiefbruders Alfons Jourdain nach Toulouse machte er sich auf, um im Heiligen Land das Erbe in der Grafschaft Tripoli anzutreten. ${ }^{90}$

Alfons Jourdain wiederum sollte es erst Jahre später gelingen, Toulouse seinem Hause wiederzugewinnen. ${ }^{91}$ Daneben suchte er die Verbindung zu Narbonne auszubauen. Zum einen führte er wieder häufiger den Titel eines Herzogs von Narbonne ${ }^{92}$, zum anderen versuchte er, wenn auch vergeblich, die Erbtochter der Vizegrafen von Narbonne durch Heirat an sich zu binden ${ }^{33}$

turicensis immunitatem secundum statuta canonum et plenissimam libertatem concedo [...] Electioni etiam episcopi vel alterius rectoris Ecclesiae faciendae per me vel per quamcunque personam me nullatenus immiscebo, nec aliquam violentiam faciam vel impedimentum praestabo quo minus electio canonice ac libere celebretur. Vgl. dazu Laurent MACE: Les comtes de Toulouse et leur entourage, $\mathrm{XII}^{\mathrm{e}}-\mathrm{XIII}{ }^{\mathrm{e}}$ siècles. Rivalités, alliances et jeux de pouvoir, Toulouse 2000 , S. 345.

86 Zur Übernahme des Titels durch Raimund von Saint-Gilles siehe KIENAST: Herzogstitel (wie Anm. 80), S. 293-302.

87 Zur Bedeutung von miles sancti Petri siehe oben Anm. 63.

88 Siehe zu ihm immer noch Guillaume de CATEL: Histoire de Comtes de Toulose avec quelques traitez et chroniques anciennes, concernans la mesme histoire, Toulouse 1623, S. 150-159; Jean-Luc DejeAn: Les comtes de Toulouse, 1050-1250, 2. Aufl., Paris 1988, S. 85-127.

89 KiEnAST: Herzogstitel (wie Anm. 80), S. 230 und 302.

90 Vgl. Jean RicharD: Le comté de Tripoli sous la dynastie toulousaine (1102-1187), Paris 1945 (Bibliothèque archéologique et historique 39).

91 Vgl. zu Alfons Jourdain CATel: Histoire de Comtes (wie Anm. 88), S. 183-198; DeJEAN: Les comtes (wie Anm. 88), S. 131-177; MACE: Comtes (wie Anm. 85), S. 24 28.

92 Kienast: Herzogstitel (wie Anm. 80), S. 303-308, der von 14 Urkunden Alfons' spricht, in denen der Herzogstitel erscheint.

93 MACE: Comtes (wie Anm. 85), S. 25-27; Aryeh GrabOїs: Une étape dans l'évolution vers la désagrégation de l'Etat toulousain au XII ${ }^{\mathrm{e}}$ siècle: l'intervention d'Alphonse Jourdain à Narbonne (1134-1143), in: AM 78 (1966) S. 23-36; Jacqueline CAILlE: Ermengarde, Viscountess of Narbonne (1127/29-1196/97). A great Female Figure of the Aristocracy of the Midi, in: DIES.: Medieval Narbonne. A City at the Heart of the Troubadour World, hg. v. Kathryn L. ReYerSON, Aldershot 2005, n X, S. 5-9, und 
und seine Herrschaft durch eine enge Zusammenarbeit mit Erzbischof Arnald von Lévezou zu festigen. ${ }^{94}$ Seinen Nachfolgern bis zu Raimund VII., der schließlich im Vertrag von Paris 1228 auf einen Gutteil seiner Rechte zugunsten des französischen Königs verzichten mußte ${ }^{95}$, gelang es nicht mehr, Einfluß auf die Wahl des Erzbischofs von Narbonne zu nehmen oder dessen Person und Stellung zur Sicherung ihrer Herrschaft zu nutzen, vielmehr war gerade der durch das Papsttum geförderte Antagonismus Narbonne -Toulouse einer der Gründe für den gegen Toulouse gerichteten Albigenserkreuzzug und die dadurch bedingte Zerstörung der Machtgrundlagen des Grafenhauses.

\section{Ausblick}

Trotz vieler Veränderungen läßt sich feststellen, daß die äußeren Grenzen der Narbona metropolis Ende des 12. Jahrhunderts immer noch die gleichen waren wie in der Spätantike: Nîmes im Osten, Uzès im Norden, Toulouse im Westen und Narbonne im Süden. Zwar hatte die spätantike Einheit zwischen civitas und Bischofssitz die Gründung germanischer Reiche auf römischem Boden nicht unbeschadet überdauert, aber das Bestreben, kirchliche und weltliche Herrschaft in Einklang zu bringen, bestand weiterhin fort.

Das Aufgehen im Westgotenreich führte zur Ausrichtung der Narbonnensis - auch in liturgischer Hinsicht - auf Toledo hin, zur Aufspaltung einiger Bistümer und zur Abspaltung anderer wie Toulouse und Uzès. Erst nach der Einnahme Septimaniens und Kataloniens durch die Franken konnte die ursprüngliche Einheit der Narbona metropolis wiederhergestellt werden, unter Anschluß

Fredric L. CheYeTtE: Ermengard of Narbonne and the World of the Troubadours, Ithaca/ London 2004, S. 14-22.

94 Siehe zu Arnald von Lévezou und dem Netzwerk seiner familiären Verbindungen Jérôme BeLmon: Aux sources du pouvoir des vicomtes de Millau (XI ${ }^{e}$ siècle), in: Vicomtes et Vicomtés (wie Anm. 83), S. 189-202 und die Genealogie S. 202 sowie DERS.: Parenté et seigneurie en Rouergue au $\mathrm{XI}^{\mathrm{e}}$ et $\mathrm{XII}^{\mathrm{e}}$ siècles: l'exemple des sires de Lévezou, in: Études aveyronnaises. Recueil des travaux de la Société des Lettres, Sciences et Arts de l'Aveyron 5 (1999) S. 75-102, bes. S. 79-81, sowie Ursula VONESLIEBENSTEIN: L'attitude de la Narbonnensis face au schisme d'Anaclet, in: Schismes, dissidence, oppositions. La France et le Saint-Siège avant Boniface VIII, hg. v. Bernard BARBICHE/Rolf Grosse, Paris 2012 (Studien und Dokumente zur Gallia pontificia 7), S. 9-29.

$95 \mathrm{Zu}$ den Bedingungen des Vertrags von Meaux-Paris siehe Élie BERGER: Histoire de Blanche de Castille, reine de France, Paris 1895, S. 136-142; zum nachfolgenden Vertrag von Corbeil, der zur endgültigen Eingliederung der Grafschaft Toulouse in die französische Krone führte, siehe Odilo ENGELS: Der Vertrag von Corbeil (1258), in: GAKGS 19 (1962) S. 114-146; Neudr. in: DERS.: Reconquista und Landesherrschaft. Studien zur Rechts- und Verfassungsgeschichte Spaniens im Mittelalter, hg. v. Erich MEUTHEN/ Ludwig VONES, München/ Wien/ Zürich 1989 (Rechts- und Staatswissenschaftliche Veröffentlichungen der Görres-Gesellschaft NF 53), S. 203-236. 
von vier Bistümern der ehemaligen Tarraconensis, da Tarragona selbst noch unter muslimischer Herrschaft stand.

Tendenzen, eigene unabhängige Herrschaftsbereiche zu begründen, führten Ende des 11. Jahrhunderts zur Abspaltung der Randgebiete - der vier jenseits der Pyrenäen gelegenen katalanischen Bistümer einerseits, des an der Westgrenze gelegenen Maguelonne andererseits. Die Initiative dazu ging von weltlichen Herrschern aus, die im Einklang zumindest mit Teilen ihres Episkopats im Papsttum eine Schutzmacht zur Stabilisierung ihrer gefährdeten Herrschaft suchten.

Die starke herrschaftliche Zersplitterung der Narbonnensis stand einer solchen Entwicklung der Grafschaft Toulouse entgegen. Zwar gab es einige Versuche, die Einheit wiederherzustellen, wie die Wiederbelebung der alten Herzogswürde von Narbonne durch die Grafen Raimund von Saint-Gilles und Alfons Jourdain zeigt, aber die Tatsache, daß sie den Anschluß ans Papsttum nicht zur Festigung ihrer Hausmacht im Languedoc nutzten, sondern zum Aufbau einer weiteren Herrschaft im Heiligen Land, ließ solche Bestrebungen wirkungslos bleiben. Hinzu kam noch die mangelnde Unterstützung durch einen Episkopat, der seit der Kirchenreform bestrebt war, jeden laikalen Einfluß auszuschalten. Als es deshalb in der Narbonnensis nicht gelang, kirchliche Interessen und weltliche Herrschaftsbildung in Übereinstimmung zu bringen, führte das Eingreifen des Papsttums Ende des 12. Jahrhunderts letztendlich nicht zur Stabilisierung, sondern zur Zerschlagung der Tolosaner Herrschaft.

\section{Summary}

Despite a lot of modifications the outward frontiers of the ecclesiastical province of Narbonne underwent little change from late antiquity to the end of the 12th century: Nîmes in the east, Uzès in the north, Toulouse in the west and Narbonne in the south. Although the rise of Germanic Kingdoms abolished the ancient unity between the local authority based in the civitas and the bishop, there still existed tendencies of a territorial combination of ecclesiastical and secular power.

During the time of the Visigoths the Narbonnensis formed part of the Kingdom of Toledo and lost two of its dioceses - Toulouse and Uzès - to the Frankish Kingdoms. After the Frankish conquest of Catalonia and Septimania the former unity of the province of Narbonne was re-established, including now the four dioceses of Catalonia, whose metropolis Tarragona was still occupied by the Muslims.

Supported by the papacy, secular rulers like the counts of Barcelona and Melgueil tried at the end of the 11th century to realize the congruence between secular and ecclesiastical frontiers in detaching the four Catalan dioceses on the other side of the Pyrenees and Maguelonne in the east from the metropolitan see of Narbonne, to strengthen their imperilled authority. 
The situation was different in the county of Toulouse, where the existence of many nearly independent lordships undid every endeavour of unification, mainly because the counts of Toulouse made use of the papacy's support only to build a further county in the Holy Land. The lack of political and ecclesiastical unity in the Narbonnensis was one of the reasons why the intervention of the papacy at the end of the 12th century contributed rather to crush the lordship of the counts of Toulouse than to stabilize it. 
